\title{
ASSESSORIA JURÍDICA POPULAR UNIVERSITÁRIA E O ACESSO À CIDADANIA PELO DIREITO À MORADIA NO MUNICÍPIO DE PORTO ALEGRE
}

\section{Marcelo Dalmás Torelly}

Acadêmico da Faculdade de Direito da PUC-RS

Membro do Núcleo de Assessoria Jurídica Popular - Najup-RS

Coordenador do Projeto Moradia

Membro da ONG HATHOR - Ações de Amor à Vida

Coordenador-Geral do Núcleo de Estudos e Pesquisa em Violência e Direitos Humanos

RESUMO: Artigo/Relato que analisa a experiência de Assessoria Jurídica Popular promovida pelo Núcleo de Assessoria Jurídica Popular - Najup, um núcleo discente, em parceria com a Prefeitura Municipal de Porto Alegre e a ONG Acesso Direitos Humanos, visando efetivar o direito fundamental à moradia e garantir a dignidade da pessoa humana em zonas de exclusão social das periferias de Porto Alegre. Objetiva o trabalho avaliar a importâncias das experiências emancipatórias na construção da identidade das comunidades e da Justiça Social. 
"É preciso que (...) desde o começo do processo, vá ficando cada vez mais claro que, embora diferentes entre si, quem forma se forma e re-forma ao formar e quem é formado forma-se e forma ao ser formado. É nesse sentido que ensinar não é transferir conhecimentos, conteúdos, nem formar é ação pela qual um sujeito criador dá forma, estilo ou alma a um corpo indeciso e acomodado. Não há docência sem discência, as duas se explicam e seus sujeitos, apesar das diferenças que conotam, não se reduzem à condição de objeto um do outro. Quem ensina aprende ao ensina e quem aprende ensina ao aprender."

Este trabalho ora apresentado é resultado direto das reflexões colidas dentro de uma experiência de Assessoria Jurídica Popular Universitária dos acadêmicos da Faculdade de Direito da PUC-RS, membros do Núcleo de Assessoria Jurídica Popular - Najup, junto as comunidades que compõem a Vila Cruzeiro do Sul, em Porto Alegre-RS. Tal trabalho foi promovido graças a um convênio celebrado entre uma Organização Não Governamental, a Acesso Direitos Humanos, e o Poder Público, através Procuradoria-Geral do Município de Porto Alegre. As experiências aqui relatadas, portanto, vêm dessa prática.

A construção dos projetos de assessoria vêm sendo feita de forma plural e coletiva nas Faculdades de Direito de todo o Brasil, em espaços similares ao de nosso núcleo, sobretudo no Nordeste do país. Esse breve artigo, que busca modestamente juntar-se como contribuição a essa construção, dialoga sobretudo com a obra de dois grande juristas brasileiros, o Professor Titular da Faculdade de Direito da PUC-SP, Celso Fernandes Campilongo, que levou para dentro das Universidades brasileiras durante a década de 1980 alguns dos mais importantes conceitos sobre a Assessoria Jurídica; e o Professor da Faculdade de Direito da Unisinos, Procurador Aposentado do Estado do Rio Grande do Sul e Advogado Popular, Jacques Távora Alfonsin - nosso orientador nessa experiência.

O trabalho divide-se em quatro partes, primeiramente irá tratar da idéia de Assessoria Jurídica Universitária, brevemente informando sobre alguns projetos previamente realizados pelo Najup e apresentando a parceria entre esse e a Acesso Direito Humanos com o Poder Público Municipal; seguirá tratando das lesões jurídicas que foram trabalhadas por nossa assessoria dentro da Prefeitura e das

\footnotetext{
${ }^{1}$ FREIRE, Paulo. Pedagogia da Autonomia. São Paulo: Paz e Terra, 1997, p.25.
} 
comunidades e estabelecendo as possibilidades e limites dos trabalhos; num terceiro momento tratará das contribuições do Projeto Moradia à construção da Justiça e de um novo Direito, e, por fim; apresentará as conclusões e resultados deste projeto inédito realizado em ampla parceria.

\section{A IDÉIA DE ASSESSORIA E O SURGIMENTO DO TRABALHO CONJUNTO: NAJUP/ACESSO/PODER PÚBLICO}

\section{1 Da idéia do trabalho universitário em Assessoria Popular}

As práticas de Assessoria Jurídica começaram a se fazer presentes no Brasil nas décadas de 1970 e 1980, fundadas na percepção das limitações da assistência jurídica tradicional, encontramos já no pensamento da professora de Faculdade do Largo São Francisco Ada Pellegrini Grinover alguns apontamentos quanto a essas limitações:

"[é necessário] rever o antigo conceito de assistência judiciária aos necessitados, porque, de um lado, a assistência judiciária não significa apenas assistência processual, e porque, de outro, necessitados não são apenas os economicamente pobres, mas todos aqueles que necessitam de tutela jurídica: o réu revel no processo-crime, o pequeno litigante nos novos conflitos que surgem numa sociedade de massas, e outros mais que podem emergir em nossas rápidas transformações sociais" ${ }^{2}$

Assim, da percepção das novas necessidades trazidas pela sociedade de massas ao mundo do Direito, começou a surgir a nova idéia de atendimento jurídico, onde inclui-se também aspectos extra-judiciais de atuação visando a proteção dos Direitos. Os serviços de assessoria são serviços de efetivação de Direitos, sobretudo dos Direitos Humanos, baseados em princípios de construção participativa da cidadania e de horizontalidade entre o cliente e o advogado, "O advogado [e/ou estudante!] coloca-se como um dentre os participantes de uma luta ou postulação jurídica que

2 GRINOVER, Ada Pellegrini, Novas Tendências do Direito Processual. Rio de Janeiro: Forense Universitária, 1990, p.247. 
beneficiará toda a comunidade. Confere a seu conhecimento profissional uma função social que suplanta a harmonização ou solução de litígios individuais. 'B.

Ao trabalhar com a idéia de construção coletiva da cidadania, os serviços inovadores, tais quais os de assessoria jurídica, passam a ter preocupações com o acesso à justiça, que nas palavras de Campilongo: "é confundido com o acesso aos tribunais. [...] O Judiciário é apenas um dos locus de atuação dos serviços legais. Havendo disponibilidade de espaços políticos, os serviços legais alternativos podem mobilizar recursos para além da arena judicial, especialmente no nível legislativo e administrativo. Os direitos sociais dependem, para sua eficácia, da implementação de políticas públicas. Nesse campo, a adjudicação clássica ainda possui limitações. Recorrer a outras arenas, além de mais rápido e eficiente, pode ser mais adequado na defesa dos direitos aos serviços sociais. Nesse jogo, a adjudicação clássica cede lugar a técnicas de negociação, barganha e arbitragem que chegam, com freqüência, a jogos com soma diferente de zero, ou seja, onde todas as partes conquistaram algumas garantias. "A

A influência das novas idéias para a proteção dos Direitos Humanos chegaram as Universidades, onde os Escritórios Modelo prestavam serviços de assistência jurídica como atividade de prática ou extensão, atuando apenas judicialmente e apenas nas demandas individuais. A reorganização de alguns desses serviços, principalmente nos estados do Nordeste, gerou o que hoje conhecemos como serviços de Assessoria Jurídica Universitária, que, em parceria com os escritórios modelos ou com advogados (sobretudo de ONG's), atuam em comunidades com Direitos violados através de capacitações que objetivem a organização da população, seguidas ou não de prestações jurisdicionais. Tais trabalhos costumam ser extremamente transdisciplinares, contando com profissionais de várias áreas; no caso dos trabalhos com Moradia e Regularização Fundiária, as equipes costumam contar com os estudantes, advogados, engenheiros, arquitetos, assessores comunitários, assistentes sociais, topógrafos, planejadores urbanos, e quantos mais profissionais forem necessários para uma ampla transformação social rumo a efetivação concreta dos direitos violados.

${ }^{3}$ CAMPILONGO, Celso Fernando. Assistência Jurídica e Realidade Social: Apontamentos para uma tipologia dos serviços legais. In DISCUTINDO A ASSESSORIA POPULAR. Rio de Janeiro: FASE, 1991, p.13

${ }^{4}$ CAMPILONGO, Celso Fernando. Op.cit., p.17. 
Outra característica típica das assessorias é que, quando "prestada fora da Defensoria Pública, como em ONG's ou por estudantes, é a de ela ser prestada gratuitamente aos assistidos, mas sem remuneração para os prestadores do serviço" ${ }^{\prime \prime}$ característica essa mantida no projeto realizado junto a Prefeitura Municipal de Porto Alegre.

\section{2 Dos primeiros projetos ao Projeto Moradia}

O Núcleo de Assessoria Jurídica Popular - NAJUP, do Rio Grande do Sul foi criado em fevereiro de 2002 pelos estudantes da Pontifícia Universidade Católica do Rio Grande do Sul, em Porto Alegre, após o contato com assessorias de todo país e de Porto Alegre em atividades do Movimento Estudantil e da Advocacia Popular.

Contando sempre com a participação voluntária de estudantes da Faculdade de Direito e com o apoio de estudantes de outros cursos e Universidades, o Najup passou a Promover Projetos de Capacitação Popular em comunidades de Porto Alegre e da Região Metropolitana, atuando em diversas áreas de interesse coletivo, como Direito da Criança e do Adolescente, Direito do Trabalho, Direito à Comunicação e Direito de Associação. Paralelamente as capacitações promoveu Projetos de Sensibilização de Estudantes e Projetos de Introdução a Assessoria Jurídica Popular em diversas Instituições de Ensino Superior do Rio Grande do Sul, entre elas a Universidade Federal do Rio Grande do Sul - UFRGS, a Universidade do Vale do rio dos Sinos - Unisinos, a Universidade de Caxias do Sul - UCS, o Centro Universitário UniRitter e a Universidade Federal de Santa Maria - UFSM.

Em março de 2003 o NAJUP, em parceria com a Comissão de Cidadania e Direitos Humanos da Assembléia Legislativa do Estado do Rio Grande do Sul, produziu a Cartilha "Um Trote no Conformismo", que foi apresentada a mais de 1500 calouros de Direito em todo o estado, trazendo informações sobre a Assessoria Jurídica Popular e a importância da construção de novas formas de atuação jurídica para a transformação social, o combate à pobreza e a efetivação dos Direitos Humanos; durante os anos de 2003 e 2004 essa cartilha chegou a

5 ALFONSIN, Jacques Távora. Assessoria Jurídica Popular. Breve apontamento sobre sua necessidade, limites e perspectivas. In REVISTA ESTUDOS JURIDICOS. V. 32, no 84 - Jan/Abr. São Leopoldo: 
diversas capitais e a algumas cidades do interior de vários estados brasileiros, entre eles Santa Catarina, Paraná, Ceará, Rio Grande do Norte.

O sucesso dos trabalhos realizados levou o Najup a se associar a diversas entidades e associações durante esses anos, principalmente junto ao Terceiro Setor, fazendo trabalhos conjuntos e em parceria. Assim, no ano de 2004, o Núcleo entrou em tratativas com a Acesso Direitos Humanos em busca de uma nova parceria para um projeto relacionado com o Direito Humano Fundamental à Moradia. Em maio do mesmo ano, através da agora parceira Acesso Direitos Humanos o Najup firmou convênio com a Procuradoria-Geral do Município de Porto Alegre para que estudantes da Faculdade de Direito prestassem estágio em assessoria na Equipe de Assistência Jurídica Municipal, trabalhando com as questões de Regularização Fundiária e Assistência em processos de Usucapião.

\section{I.3 Da parceria com a Prefeitura Municipal de Porto Alegre}

Segundo dados do Mapa da Irregularidade Fundiária, publicado pela Prefeitura Municipal de Porto Alegre ainda em julho de 1999, existiam à época, mais de duzentos e oitenta mil famílias, vivendo em áreas públicas e privadas de maneira inadequada do ponto de vista do seu direito à moradia, mesmo que em tal dado ficassem excluídos os loteamentos irregulares e os clandestinos, de acordo com a distinção consagrada por José Afonso da Silva ${ }^{6}$. A partir de tais dados a Prefeitura Municipal de Porto Alegre passou a formular políticas públicas relacionadas a efetivação do Direito à Moradia.

O Najup, ao iniciar o trabalho com a Prefeitura, não podia abrir mão das características dos serviços inovadores que caracterizam as assessorias, e para tanto, precisava encontrar dentro da organização do poder público um espaço onde pudesse trabalhar de modo transdisciplinar. Tal espaço foi encontrado na Equipe de Assistência Jurídica Municipal, instituída pela Lei Municipal n.ำ 7.433/94 e alteração posterior, combinada com o art. $16 \S$ único da Lei Federal n.. 1.060/50. Tal equipe atuava em ações de usucapião urbano das comunidades que se organizavam e demandavam a ação via Orçamento Participativo.

Editora Unissinos, 1999, p.61.

${ }^{6}$ SILVA, José Afonso da. Direito Urbanístico Brasileiro. São Paulo: Malheiros, 1995, p. 307-308. 
A Equipe, composta por Procuradores do Município, Assessores Comunitários, Engenheiros, entre outros profissionais, propiciava o espaço para que iniciássemos um trabalho de interlocução com o povo, buscando agir conforme 0 ensinamento de Campilongo que dizia que: "a falta de consciência a respeito dos próprios direitos e a incapacidade de transformar suas demandas em políticas públicas são combatidas com o trabalho de esclarecimento e organização popular para a defesa de seus interesses" ${ }^{\prime \prime}$. Assim passamos a buscar informar, e portanto formar, a população sobre seus direitos, transformando, em nós e neles próprios, a idéia de seu protagonismo político na construção dos Direito Humanos, ao mesmo tempo que buscávamos potencializar o trabalho forense da Equipe, contribuindo na organização de dados e no trabalho peticional.

\section{DAS DEMANDAS E DAS LESÕES QUE AS MOTIVAM: QUANTO A IMPOSSIBILIDADE DE UM SERVIÇO ESTRITAMENTE JUDICIAL}

\section{II.1 As demandas Coletivas e seus agentes}

A idéia de que não existem direitos sem que existam pessoas como seus titulares, que fundamenta a noção de Direito Subjetivo, é desde sempre comum a todos os juristas, mas a identificação dos sujeitos dos direitos e deveres nem sempre obedece a lógica cartesiana dos modernos ordenamentos jurídicos. A medida que os Direitos Humanos evoluíram de sua primeira geração, os direitos liberdades, para uma segunda geração, a dos direitos sociais, iniciou-se na doutrina o debate sobre a viabilidade de se efetivar esses direitos, sobretudo em países onde - Estado Social não possuía um desenvolvimento pleno - caso do Brasil -, os novíssimos direitos de terceira, e quiçá de quarta geração, desafiam ainda mais a antiga lógica. Boa parte do problema passa pela incapacidade de se identificarem os titulares dos direitos e dos deveres em questão, na maior parte das vezes para além do Estado.

Sob influência do individualismo liberal a prática jurídica acabou por se conformar com uma realidade em que um indivíduo busca seus direitos ante a um

\footnotetext{
${ }^{7}$ CAMPILONGO, Celso Fernando. Op.cit., p.11.
} 
outro, ou ante ao Estado. A polêmica em torno da efetivação dos Direitos Humanos de segunda geração inicia-se na impossibilidade de sanar a lesão através efetivação individual do direito, que por ser social é, por excelência, coletivo, e na dificuldade que alguns setores da sociedade tem em aceitar que não é apenas o Estado o pólo passivo dessas demandas.

O ser humano, lesado em seus Direitos junto à sociedade, passa a ser desumanizado, sofrendo de novas e constantes violações de direito de toda sorte, ao analisar as carências dessa verdadeira vítima social o Professor Jacques Alfonsin aponta que "observando a vítima, vê-se que ele é um sujeito que sofre de três carências principais, capazes de sacrificar a sua própria dignidade, como pessoa e cidadão: são as carências do ter, do poder e do ser. [...] Basta a comparação desses déficits com as três ordens jurídicas principais da Constituição Federal para concluir que ele não está amparado nem pela ordem econômica, nem pela ordem política e nem pela ordem social. (grifos no original), ${ }^{\text {. }}$.

A idéia de Assessoria Jurídica parte do pressuposto que só o saneamento dessas três carências é capaz de devolver a dignidade e o status humano ceifados da pessoa, assim busca não apenas o atendimento judicial da demanda rotineiramente prestado aos indivíduos por serviços de assistência e escritórios modelo -, mas sim a organização político-social dos coletivos com direitos violados, despertando-Ihes a cidadania, e apenas após isso, a eventual prestação jurisdicional para as comunidades - coletivos de pessoas - das ações necessárias a materialização de direitos.

\section{II.2 A lesão jurídico-social a ser sanada}

Tem-se, portanto, que a lesão que a Assessoria Jurídica busca sanar é muito maior e mais ampla que a lesão sanável pelo meio estritamente judicial, pois "o sujeito que procura a assessoria jurídica popular, sabidamente, está entre as maiores vítimas daquelas três formas de violação de direitos, vítimas essas que, embora sintam a dignidade ameaçada ou ferida, nem sempre têm consciência dos poderes de socorro que a primeira pode lhe prestar. ${ }^{\prime \theta}$.

8 ALFONSIN, Jacques Távora. Op.cit., p.53.

9 ALFONSIN, Jacques Távora. Op.cit., p.54. 
As lesões que se materializam no indivíduo são sempre praticadas contra a coletividade. O exemplo do Direito ao Meio-Ambiente, um Direito Humano de quarta geração, é bastante emblemático, mesmo que apenas alguns sofram de forma imediata com a poluição dos rios (por exemplo, os que precisam da água daquele rio para viver), toda a humanidade se prejudica da violação a longo prazo. No caso do direito fundamental à Moradia, o sofrimento individual é geralmente, mas não necessariamente - por isso ser esse um direito de segunda geração -, comum a muitos outros sujeitos que dividem um espaço geográfico precariamente organizado. Deste modo, a única forma de garantir o direito à moradia, que deve ser digna, é não apenas garantir a propriedade do imóvel ao sujeito, mas também lhe fornecer todos os aparelhos necessários a manutenção de uma vida saudável, tais quais a rede de esgoto, o acesso a água e a luz elétrica, a urbanização do espaço físico, etc.

Quanto a existência jurídica de um direito á moradia, esclarece com maestria o professor da PUC-RS e Juiz de Direito, Ingo Sarlet, ao dizer que com: “... a recente incorporação do direito à moradia no art. $6^{\circ}$ da Constituição Federal de 1988, não há mais como negar que a moradia (a despeito de já haver previsão expressa a respeito, como dão conta - entre outro exemplos - o instituto do usucapião especial urbano e rural previstos nos artigos 183 e 191 da nossa Carta Magna respectivamente) restou guinada à condição de direito fundamental, compartilhando, de tal sorte, de dupla fundamentalidade material (ligada ao grau de importância do bem assegurado pela ordem jurídica) e formal (representada pela especial força normativa e proteção outorgada pela Constituição escrita) que caracteriza os direitos fundamentais. ${ }^{10 "}$

Assim, para garantir o Direito à Moradia acima referido, as demandas judiciais que surgem da organização de comunidades que vivem em moradias precárias envolvem, além de ações judiciais plúrimas e coletivas, todo um trabalho de organização e regularização fundiária. O serviço legal tradicional se preocuparia apenas em garantir o status de proprietário ao sujeito com direitos violados, mas o serviço de assessoria, com suas "demanda alargadas" passa a se preocupar com a

10 SARLET, Ingo Wolfgang. Estado Social de Direito, a Garantia Fundamental da Propriedade e Proibição de Retrocesso. REVISTA DE DIREITO DA ASSOCIAÇÃO DOS PROCURADORES DO NOVO ESTADO DO RIO DE JANEIRO, Lumen Juris, ํ5 , dez 2000, p.141. 
constituição de toda uma rede de direitos capazes de garantir a dignidade e a cidadania através da inserção do sujeito como sujeito de direitos nas três ordens constitucionais acima referidas em citação do professor Alfonsin: a econômica, a política e a social.

Ao enfrentar o problema de forma coletiva e transdisciplinar se efetivam de forma mais plena os direitos e se garante que tal efetivação se mantenha no tempo, pois é afastada a precariedade presente em projetos que garantem alguns direitos a um indivíduo deixando seus pares totalmente a descoberto e o próprio apenas parcialmente protegido. Porém, na busca de efetivação de direitos coletivos algumas dificuldades surgem de forma mais intensa, os problemas de legitimação processual se multiplicam pelo número de autores e de réus, a má descrição dos lotes pode obstaculizar os Direitos, a falta de provas documentais pode levar a necessidade de audição de um sem número de testemunhas e a irresponsabilidade de uma das partes - que não se entende enquanto protagonista do processo - pode ser lesiva a todas a demais, por isso a importância vital de todo processo extra-judicial de organização da comunidade, bem como da coleta de provas e topografia de áreas a serem usucapidas.

\section{II.3 Quanto à impossibilidade do saneamento da lesão pelo meio estritamente judicial}

Os "Direitos coletivos, entendidos como não passíveis de fruição individual e exclusiva, comportam estratégias de tutela que também escapam à lógica individualista"11 , assim não é possível pensar na solução do problema das moradias irregulares apenas na esfera jurídica. Os constantes conflitos deflagrados em várias cidades brasileiras quando o Poder Público busca "realocar" pessoas em moradias de situação irregular para novas áreas da cidade mostra isso com clareza, a quebra de redes de convívio social e a alteração do espaço geográfico onde tais redes se desenvolvem é bastante complicada, assim as menores alterações a serem geradas na vida das pessoas devem ser debatidas, e se possível contornadas, de modo a evitar justificável revolta.

\footnotetext{
${ }^{11}$ CAMPILONGO, Celso Fernando. Op.cit., p.08
} 
Para tanto mostra-se absolutamente necessária a articulação dos serviços jurídicos com as associações comunitárias da região, mas essa articulação com o povo não se restringe à parte jurídica do projeto, pois os engenheiros e arquitos terão de adaptar-se as possibilidades de trabalho oferecidas pelas vilas no momento de construir os acessos e urbanizar os espaços públicos, por exemplo. O total descolamento entre a realidade fática e a prevista nos planos diretores também é um obstáculo à via estritamente judicial, em qualquer grande projeto de urbanização de áreas irregulares a possibilidade de reorganização conforme o plano diretor é quase nula, sendo necessários acordos com a comunidade para a remoção e reconstrução de algumas residências e alguma flexibilidade do Poder Público para alterar traçados de vias públicas.

Outro problema comum à relação com o povo e que não é estritamente jurídico-judicial é o relativo aos critérios mínimos estabelecidos pelo poder público para ingressar com as ações. É difícil fazer o popular que, por exemplo, mora em um residência inferior a $39 \mathrm{~m}^{2}$ entender que tal moradia não atende ao critério estabelecido como de "dignidade humana", sendo que ele sempre ali residiu; é importante o trabalho de conscientização para evitar que as ações que visam proteger os cidadãos e garantir a sua dignidade passem a parecer, para os mesmos, como uma arbitrária troca de lugares na vila, onde alguns serão "premiados" com casas novas e outros com o título de proprietários, enquanto outros serão removidos da vila para outro local, ou, simplesmente, passarão um longo período aguardando o solução de sua situação no judiciário.

Tais trabalhos, notoriamente extra-judiciais, visam garantir que o próprio povo não impeça o processo por não o entender, e, muito mais, que o mesmo se torne agente ativo do trabalho de construção de seu Direito. Esse tipo de demanda, claramente incomum às assistências, enquadra-se com perfeição nas características de uma assessoria. 


\section{DA BUSCA POR UM NOVO DIREITO E POR JUSTIÇA SOCIAL}

\section{1 A busca por Acesso à Justiça e a necessidade de um Direito Popular}

Entendidos os preceitos da assessoria e a importância fundamental da mesma na dinamização do mundo jurídico resta agora a análise do objetivo máximo da mesma, presente não só no Projeto Moradia, mas em todos os projetos do Najup: A Construção da Justiça.

O afastamento entre povo e Direito, característico da época moderna em oposição à idéia romana de Direito, é um dos principais obstáculos a construção da Justiça, e tal fato fica claríssimo na afirmação de Bachof: "A relação do homem com a lei mudou totalmente! Isso pode ser visto, atualmente através de um sentimento generalizado de profundo mal estar e ainda de radical desconfiança; de uma desconfiança que, salvo para uma minoria, não se baseia verdadeiramente em um conhecimento racional das causas, senão na impressão dominante, imprecisa, mas não por isso falsa, de que a lei, em outro tempo escudo da liberdade e do Direito, converteu-se hoje, precisamente, em uma ameaça para esses bens" ${ }^{\prime 2}$.

Os conflitos entre Direitos Humanos e Direitos Patrimoniais são um ótimo exemplo de um lócus onde as relações de poder colonizaram e destruíram as relações de Direito. A luta por uma mudança de mentalidade é fundamental para a garantia dos Direitos Humanos e do Acesso à Justiça, a construção da Justiça depende da fortificação da idéia da prioridade do humano sobre o patrimonial, ou, nas palavras de Ruy Portanova ao analisar conflito entre partes que buscam resguardar direitos de fundamentalidades diferentes: "Os doutrinadores afirmam que, havendo necessidade de sacrificar o direito de uma das partes, sacrifica-se o patrimonial, garantindo-se os direitos fundamentais, se a outra opção for esta. Não bastasse a doutrina apontar essa solução, o bom senso impõe tal direcionamento"13

Para além da construção doutrinária apontada pelo llustríssimo Doutor Portanova, e da construção jurisprudencial, para a qual o próprio contribui, é necessário o trabalho alternativo também na prática da advocacia, construindo

\footnotetext{
${ }^{12}$ BACHOF, Otto. Jueces y Constituición. Madri: Civitas, 1987, p.48. (tradução livre)
} 
saídas que quebrem com a ótica individualista e opressora do Direito moderno, tais alternativas surgem "especialmente a partir da década de 60 [quando] a ajuda jurídica vai, rapidamente, trocando a imagem de instrumento de controle social pela concepção da assistência legal enquanto ferramenta de um 'acesso igualitário ao direito"14. Pensar a construção da Justiça como uma construção dos tribunais é ignorar a necessidade de Justiça em todas as relações humanas, e é, portanto, perder de vista que o bem-viver humano em sociedade depende da compreensão de todos os agentes enquanto agentes políticos capazes de agir e transformar discursivamente o mundo. Nessa perspectiva, resgatada do passado, temos um refuncionalização do operador jurídico, que passa a ser agente horizontal em um processo onde as próprias partes agem no sentido de construir o bem comum, e onde o povo deixa de receber assistência e passa a construir, com suas forças e a seu tempo, a sua própria emancipação.

\section{2 As maiores dificuldades do Projeto}

Ao abandonar a perspectiva assistencialista nos deparamos com dificuldades bastante novas, relativas sobretudo ao trabalho extra-judicial junto as populações, os maiores problemas são: primeiramente o problema ao qual Jacques Alfonsin chamou de "massificação"15, e; em segundo lugar a dificuldade - inerente ao nosso projeto de prestar assessoria num espaço inicialmente projetado para servir como assistência.

Quanto ao problema da massificação as palavras do Professor Alfonsin são tão claras que sua citação dispensa maiores delongas, por isso sentimo-nos autorizados a reproduzi-la integralmente:

"Dos vícios próprios da massificação, capazes de prejudicar a assessoria jurídica popular, os seis mais visíveis talvez, sejam os seguintes:

\footnotetext{
${ }^{13}$ PORTANOVA, Ruy. Provimento à Recurso de Agravo de Instrumento no processo no 598360402 , na 19ª Câmara Cível do Tribunal de Justiça do Rio Grande do Sul. Porto Alegre, 1999.

${ }^{14}$ CAMPILONGO, Celso Fernando. Op.cit.,_p.19

15 "A palavra massificação está sendo usada aqui, no mesmo sentido que the dá o Professor [Ernani Maria] Fiori, [...] ou seja, como aquela forma de consideração do povo como objeto e não como sujeito da sua própria emancipação." ALFONSIN, Jacques Távora. Op.cit., p.59.
} 
a) despersonalizar e descaracterizar a demanda popular, com posturas do tipo "eu trabalho é pela classe", "eu trabalho é pelo partido", "eu trabalho é pela minha igreja"[...]

b) escolher por si própria e segundo suas conveniências, os seus interlocutores, ouvindo somente lideranças ou quem se apregoa como tal[...]

c) ignorar nuances capazes de bloquear a prestação dos seus serviços, como o desrespeito a aspectos culturais dos assistidos, do tipo de grau de consciência da injustiça que estão sofrendo, religião, folclore, concepção diferente do que seja moral ou costume[...]

d) desprezar a participação do povo na realização de trabalhos que ele próprio está disposto a fazer e pode fazer. [...]

e) assumir ela própria a liderança da demanda popular, atropelando lideranças escolhidas pelo povo, para encaminhamento de questões que, não raro, ultrapassam o serviço jurídico. [...]

f) "deixar-se usar" por demandas que nem sempre têm o selo da legitimidade propriamente popular, mas são assumidas só pelo fato de provirem daquele meio. [...]"16

Quanto ao segundo problema, mais característico do Projeto Moradia, de buscar prestar assessoria em um espaço pensado como assistencial, os "vícios" são menos catalogáveis, mas nem por isso menos fatais aos objetivos do projeto. $A$ necessidade de uma constante autocrítica é uma das principais constatações que temos e que visa evitar que o projeto perca suas características inovadoras; tal é preciso, pois o atendimento judicial tende a consumir boa parte do tempo dos membros do projeto, fazendo com que o atendimento extra-judicial ao povo - que orienta a ética do trabalho - acabe ficando relegado a segundo plano, e que o projeto caia na mesmice do assistencialismo, diminuindo seu potencial transformador da sociedade.

As constantes idas a campo reduzem tal problema e ainda permitam um maior controle sobre os seis "vícios mais visíveis" apontados acima, além disso, a renovação das pessoas envolvidas no projeto e a circulação dos membros da 
equipe em setores diferentes do trabalho (pesquisa, atendimento, capacitação, organização...) ajuda a garantir uma visão global da ação e a evitar o enraizamento que leva o agente a julgar-se mais parte do processo que os próprios populares e a objetificar o problema jurídico-social e seus agentes enquanto obstáculos a serem vencidos.

\section{CONCLUSÕES}

Ao fim do convênio firmado com a Procuradoria-Geral do Município da Prefeitura Municipal de Porto Alegre, resta ao Najup , bem como a Acesso Direitos Humanos, a felicidade de perceber que existe hoje, dentro do Poder Público, espaço para ações com "demandas alargadas" que visem uma melhoria global da qualidade de vida das comunidades carentes, efetivando Direitos Humanos em rede e garantindo a manutenção de tais Direitos no tempo. As adversidades encontradas pelo projeto mostram como ainda resta um longo caminho a percorrer para que as iniciativas de assessoria jurídica se consolidem dentro de espaços estatais, mas deixa claro que tal caminho pode ser trilhado.

A emancipação social do povo é hoje um dos principais desafios da efetivação dos Direitos Humanos no terceiro mundo, diferentemente do "mundo desenvolvido" nossa luta não é apenas pela satisfação de certas necessidades, mas sim pela garantia da dignidade humana e da cidadania a todos, de modo a tornar possível que os próprios indivíduos construam seus Direitos e participem como protagonistas da construção da Justiça em uma sociedade democrática.

O trabalho de assessoria prestado junto a comunidades da Vila Cruzeiro do Sul deixa claro a importância de levar a todos condições adequadas de vida, e o fato de tal trabalho ter sido executado em parceria com a comunidade e com entidades da sociedade civil, mostra a importância dessa construção partir da própria comunidade e ser executada por toda a sociedade, e não apenas pelo Estado.

A execução de projetos como o Projeto Moradia faz crer ser possível o trabalho coletivo em prol da sociedade, mostrando ser possível em um único projeto atingir diversos fins, como: 1- Ampliar a formação acadêmica de estudantes universitários de modo a melhor prepara-los para a promoção de mudanças sociais;

${ }^{16}$ ALFONSIN, Jacques Távora. Op.cit,, p.59-61. 
2- Potencializar o trabalho do Poder Público, oxigenando-o e tornando-o mais apto ao atendimento das demandas sociais; 3- Diminuir o sofrimento dos flagelados sociais de nossas cidades; 4- Construir de forma coletiva uma política pública de reurbanização; entre tantos outros mais.

A importância dada hoje à regularização fundiária e ao acesso a terra urbana certamente trará como frutos, em um futuro próximo, uma sociedade mais justa e mais capaz de lidar com seus problemas e contradições. Ao fim do convênio que permitiu tal experiência, o Núcleo de Assessoria Jurídica Popular sente-se honrado por ter sido um dos protagonistas deste trabalho, e, espera, muito em breve, poder tornar outros projetos de construção da Justiça Social possíveis. 


\section{BIBLIOGRAFIA}

ALFONSIN, Jacques Távora. Assessoria Jurídica Popular. Breve apontamento sobre sua necessidade, limites e perspectivas. In REVISTA ESTUDOS JURÌDICOS. V. 32, no 84 - Jan/Abr. São Leopoldo: Editora Unissinos, 1999, p.51-67.

BACHOF, Otto. Jueces y Constituición. Madri: Civitas, 1987.

BOFF, Clodovis. Como Trabalhar com o Povo. Petrópolis:Vozes, 1984.

BONAVIDES, Paulo. Curso de Direito Constitucional. São Paulo: Malheiros, 2003.

CAMPILONGO, Celso Fernando. Assistência Jurídica e Realidade Social: Apontamentos para uma tipologia dos serviços legais. In DISCUTINDO A ASSESSORIA POPULAR. Rio de Janeiro: FASE, 1991, p.8-p.28.

FERNANDES, Edésio (Org). Direito Urbanístico e Política Urbana no Brasil. Belo Horizonte:Del Rey, 2001.

FREIRE, Paulo. Pedagogia da Autonomia. São Paulo: Paz e Terra, 1997.

GRINOVER, Ada Pellegrini, Novas Tendências do Direito Processual. Rio de Janeiro: Forense Universitária, 1990.

LAFER, Celso. A Reconstrução dos Direitos Humanos. São Paulo: Companhia das Letras, 2003.

SANTOS, Boaventura de Sousa. O Discurso e o Poder. Porto Alegre:Sérgio Fabris Editor, 1988.

SARLET, Ingo Wolfgang. Estado Social de Direito, a Garantia Fundamental da Propriedade e Proibição de Retrocesso. REVISTA DE DIREITO DA ASSOCIAÇÃO DOS PROCURADORES DO NOVO ESTADO DO RIO DE JANEIRO, Lumen Juris, vo 5, dez 2000, p. 131-150.

SILVA, José Afonso da. Direito Urbanístico Brasileiro. São Paulo: Malheiros, 1995 